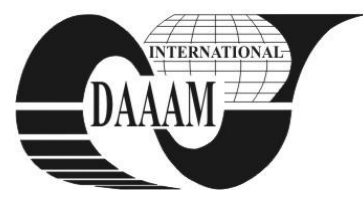

Annals of DAAAM for 2011 \& Proceedings of the 22nd International DAAAM Symposium, Volume 22, No. 1, ISSN 1726-9679 ISBN 978-3-901509-83-4, Editor B. Katalinic, Published by DAAAM International, Vienna, Austria, EU, 2011 Make Harmony between Technology and Nature, and Your Mind will Fly Free as a Bird Annals \& Proceedings of DAAAM International 2011

\title{
DATA MART FRAMEWORK FOR PRODUCTION ROUTE SELECTION
}

\author{
SAHNO, J[evgeni]; SAVIMAA, R[aul]; KANGILASKI, T[aivo]; OPIK, R[ain]; \\ MALEKI, M[eysam] \& MACHADO, V[irgilio] C[ruz]
}

\begin{abstract}
Having an efficient business model can be achieved by improving existing business processes and excellent Knowledge Management. In our research it is suggested to use Enterprise Architecture management approach to improve the effectiveness of developed solution. We combine that framework with Knowledge Management approach based on data mart structure and introduce a novel solution for production route estimation.
\end{abstract}

Keywords: knowledge management, ERP, PDM, IS, SOM

\section{INTRODUCTION}

The aftermath of the global financial crisis has caused a tough situation in enterprises, especially in the machinery sector, which has forced to reorganize their business processes to be more efficient (Polyanchikov et al., 2010). In most cases process improvement has been followed by changes in their Information Systems (IS). The current paper suggests using an Enterprise Architecture (EA) concept, which enables changes of business processes combine with analysis of changes on IT systems, data management, and infrastructure levels.

The aim of the current research is to support production activities by sustaining the technological knowledge of the company. A technological knowledge management (KM) approach is proposed that enables to store, classify and extract item/project production route data from a Data Mart (DM).

Enterprises which are dealing with large number of manufacturing tasks can benefit from the proposed framework. Every project has a specialized production technology and every item has its specific production route. Often the technical documentation of projects is stored in separate files, which could lead to difficulties in finding a required document. Also majority of technological knowledge is stored in the brains of the engineers. When the engineer decides to leave the company, this knowledge is often lost from the enterprise.

The framework presented in this research combines Computer Aided Design (CAD), Product Data Management (PDM), Enterprise Resource Planning (ERP) systems, and Operation Data Store (ODS) systems. It facilitates storing, searching and assessing existing production routes in the DM.

\section{BACKGROUND}

EA is widely used by organizations to respond quickly to changes. It is a rigorous description of the enterprise structure including enterprise goals, business processes, roles, organizational structures and behaviors, business knowledge, software applications, and computer systems. EA is employed as a reference that enables the organization to assess the impact of the changes on each of EA components.

In this research EA based approach provides a strong framework which will help the planning, developing as well as implementing the required business changes.

KM systems facilitate organizational learning and knowledge creation. They are designed to provide a rapid feedback to decision makers, encouraging behavioral changes in employees and improving business performance. As the organizational learning process continues and its knowledge expands, the knowledge-creating company works to integrate its knowledge into its business processes, products and services. This helps the company become a more innovative and agile provider of high-quality products and customer services, as well as formidable competitor in marketplace (O'Brien \& Marakas, 2008).

KM refers to a multi-disciplined approach to achieving organizational objectives by making the best use of knowledge. There are various components in a decision-making environment, including collection of data, storage of data, data analysis and knowledge discovery (Shevtshenko et al., 2009).

A PDM system is a component of the IS for managing product related data generated by CAD systems. This system allows maintaining Bill of Materials (BOM), visibility of relationships between parts and assemblies and quick access to standard items, BOM structure, and files for reuse and derivation. A PDM system reduces the risk of using incorrect design versions (Saaksvuori \& Immonen, 2008). Integration with a CAD/CAM system permits describing the BOM and the parts of manufacturing process (Portjanski, et al., 2010).

The ERP system is integrated cross-functional software that supports the management of basic business processes, improving efficiency, agility, and profitability through the reengineering of processes (De Geus, 1988).

\section{KNOWLEDGE MANAGEMENT}

This research reveals the importance of collecting, storing, and sharing technological knowledge inside company and with partners. The proposed framework can be applied by practitioners of manufacturing companies from different fields of industry that produce physical goods.

The purpose of the KM is to retrieve either explicit or tacit knowledge that resides within people, artifacts, or organizational entities. Also, the knowledge might reside outside the organizational boundaries, including consultants, competitors, customers and employees of the organization. The $\mathrm{KM}$ process benefits most directly from two sub-processes: externalization and internalization that help capture the tacit knowledge and explicit knowledge, respectively. During externalization, explicit knowledge (e.g. printed information or databases) is converted into tacit (i.e. knowledge in mind that is used for production of goods in manufacturing). Similarly, during internalization, tacit knowledge (as employees' experiences) is converted into explicit by formalizing it in a data warehouse or manuals (Becerra-Fernandez et al., 2004).

We suggest following the steps described by the EA concept in the Figure 1. The EA starts with analysis of business process, which is required to enable a storage and reuse of the knowledge related to production routes.

The second step is analysis of IS requirements. IS should permit users to store the production routing data and facilitate a reuse of this data when creating a new production route. 


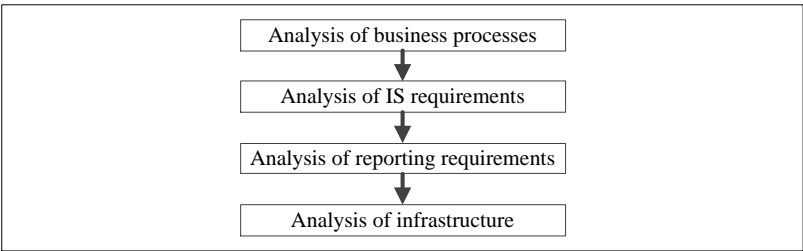

Fig. 1. Overview of the structure of the Enterprise Architecture

Step 3 consists of analysis of reporting requirements. Reporting simplifies the process of optimal production route creation based on criteria like time, cost and failure data.

The final step is analysis of infrastructure, where the store for DM should be added to existing infrastructure.

\section{DATA MART STRUCTURE FOR STORING TECHNOLOGICAL KNOWLEDGE}

The current research is focused on the design of framework for technological knowledge management for manufacturing enterprises. Elaborated framework can be used for improvement of profitability and sustainability of manufacturing processes in industrial enterprises and collaborative networks.

Based on analysis and modeling we suggest that routing data storage and search framework should be consist of following levels: Input data level, Data storage level, Data analysis level, and Output data level represented in the Figure 2.

Input data level. The CAD data is converged to the PDM system where the product BOM is prepared. The received data from the PDM and also from a CRM system is moved to Operational data store (Zahharov et al., 2009). The enterprise data is managed by an ERP system. The integration is made through a database which shares all functions and data processing applications in the company.

Data storage level. The data from the Input data level is consolidated in an Operational data store. The data necessary for production route selection is replicated to a DM. We propose searching for production routes through the ERP using data from the DM. This implies a classification of products by item name, dimensions, weight, material standards and other properties.

Data analysis level. In order to choose the most efficient production route, we propose to use Kohonen's Self Organizing Maps (SOM). SOM is constructed on criteria such as production route time, cost, and faults that eventually assist in decision making procedure to select the most cost-effective route.

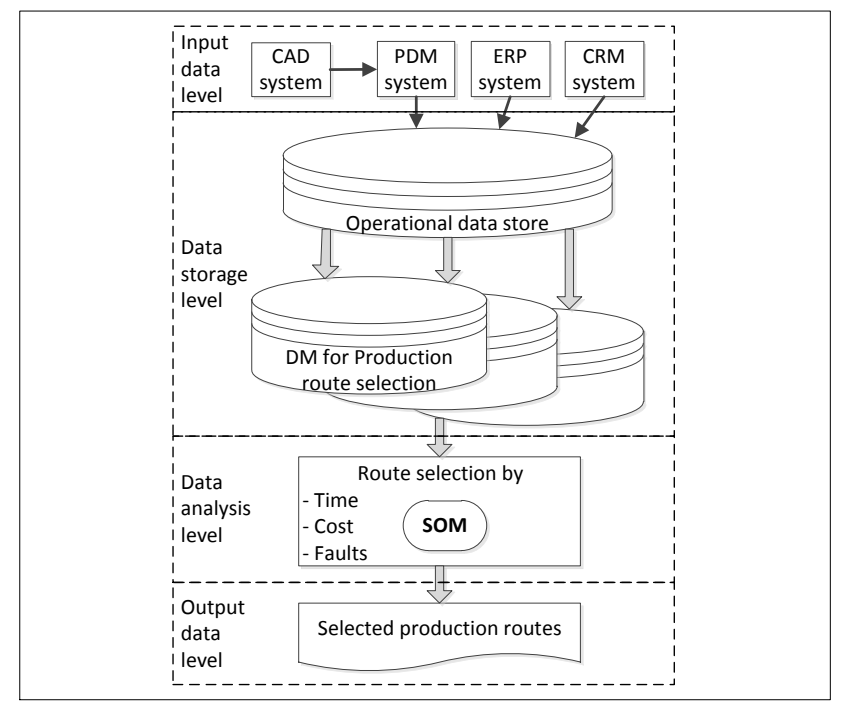

Fig. 2. Framework for search, selection and storage of production route
Output data level. The most suitable production route is selected and sent back to the ERP system for modifications.

This introduced novel framework is a specialized modification to EA concept in all four steps of EAM. Preliminary modelling showed that the framework is also suitable for virtual enterprises where processes, information systems and infrastructure of participating organizations are only partially and temporarily integrated to achieve common goals or to produce a specific product.

\section{CONCLUSIONS}

Modern knowledge management techniques help companies to capture, store and re-use large amount of explicit and tacit information in order to improve their management decisions as well as production activities. As the result of the current research, the paper suggested an EA management approach and presented a novel unified framework of technological KM systems. The framework enables to elaborate a new order route for production, based on enterprise goals and existing information from CAD, PDM, CRM and ERP systems by applying a DM approach. The future research will departure form presented results and will concentrate on further detailed specification of suggested solution for virtual enterprises.

\section{ACKNOWLEDGEMENTS}

The research was partially financed by Estonian Science Foundation grant ETF7693. Hereby we would like also thank the Estonian Ministry of Education and Research for targeted financing scheme SF0140113As08, European Social Fund's Doctoral Studies and Internalization Programme DoRa and financial funding for doctoral study from MIT-Pt/EDAMIASC/0033/2008 project.

\section{REFERENCES}

Becerra-Fernandez, I.; Gonzalez, A. \& Sabherwal, R. (2004). Knowledge Management, Solutions and Technologies, Pearson Education, Upper Saddle River, NJ

De Geus, A. (1988). Planning as Learning, Harvard Business Review

O'Brien, J. A. \& Marakas, G. M. (2008). Management Information Systems, The McGraw-Hill Companies, Inc., pg. 63

Polyanchikov, I.; Pribytkova, M.; Shevtshenko, E. \& Kangilaski, T. (2010). E-Maintenance Framework for the Collaborative Network of SME-S, Annals of DAAAM for 2010 \& Proc of the 21st Intn DAAAM Symposium, 20-23rd October 2010, Zadar, Croatia, ISSN 1726-9679, ISBN 9783-901509-73-5, Katalinic, B. (Ed.), pp. 0877-0878, DAAAM International Vienna, Vienna

Portjanski, L., Nekrassov, G., Zahharov, R., Shevtshenko \& E. (2010). Logbuild - CAD/CAM system for log houses. Mechanika, Issue 6, pp. 58-65

Saaksvuori, A. \& Immonen, A. (2008). Product Lifecycle Management, Springer, Third Edition

Shevtshenko, E., Karaulova, T., Kramarenko, S. \& Wang, Y. (2009). Manufacturing project management in the conglomerate enterprises supported by IDSS. Journal of Achivements in Materials and Manufacturing Engineering, Vol. 33 Issue 1, 94-102

Zahharov, R.; Shevtshenko, E. \& Karaulova, T. (2009). Integrated CAD/ERP Framework for Modular Construction Industrialization Through Lean Manufacturing Concepts, Annals of DAAAM for 2009 \& Proc of the 20th Intn DAAAM Symposium, 25-28th November 2009, Vienna, Austria, ISSN 1726-9679, ISBN 978-3-901509-70-4, Katalinic, B. (Ed.), pp. 0591-0592, DAAAM International Vienna, Vienna 